\title{
Significados das práticas corporais no tratamento da dependência química
}

Giuliano Gomes de Assis Pimentel ${ }^{1}$

Edna Regina Netto de Oliveira ${ }^{2}$ Aparecida Paulina Pastor ${ }^{3}$

PIMENTEL, G.G.A.; NETO-OLIVEIRA, E.R.; PASTOR, A.P. Significance of corporal practices in treating chemical dependence. Interface - Comunic., Saúde, Educ., v.12, n.24, p.61-71, jan./mar. 2008.

The aim of this study was to analyze the social representations of women with chemical dependence, regarding the contribution of corporal practices towards their process of recovery and reintegration into society. Fourteen women hospitalized in a treatment institution were interviewed and observed in relation to their participation in a corporal practice program, systematized in the form of games and exercises. Their words and practices showed contradictions between feelings, justifications and perspectives with regard to the use of their own bodies. Based on these results, it was sought to understand how the social conditions of their lives mediated the way these women organized themselves to benefit their health.

Key words: Body. Health. Chemical dependence. Corporal practice. Physical Education.
O objetivo deste estudo foi analisar as representações sociais de mulheres dependentes químicas sobre a contribuição das práticas corporais em seu processo de recuperação e inserção na sociedade. Quatorze internas de uma instituição de tratamento foram entrevistadas e, também, observadas em relação à participação em um programa de práticas corporais, sistematizadas na forma de jogos e exercícios. As falas e práticas demonstraram contradições entre sensações, justificativas e perspectivas em relação ao uso de seus corpos. Com base nos resultados, se buscou compreender como as condições sociais de vida medeiam o modo pelo qual essas mulheres se organizam em benefício de sua saúde.

Palavras-chave: Corpo. Saúde.

Dependência química. Práticas corporais. Educação Física.

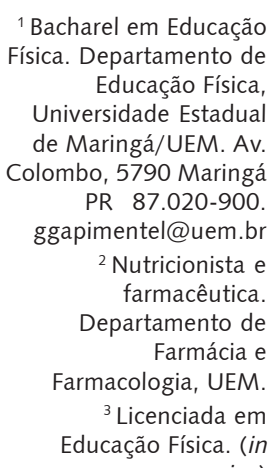

1 Bacharel em Educação Física. Departamento de Educação Física, Universidade Estadual de Maringá/UEM. Av. Colombo, 5790 Maringá PR 87.020-900. ggapimentel@uem.br

${ }^{2}$ Nutricionista e farmacêutica. Departamento de Farmácia e Farmacologia, UEM.

${ }^{3}$ Licenciada em Educação Física. (in memorian) 


\section{Introdução}

O uso de drogas é influenciado por múltiplos aspectos, sendo difícil prever quais pessoas ou comportamentos desencadearão o consumo. Se a complexidade de fatores é inerente a essa problemática, não é surpresa que sejam necessárias diferentes práticas para se efetivar o tratamento, podendo-se citar, entre elas, a educação para o lazer do dependente químico por meio de práticas corporais recreativas (Gimeno et al., 1998).

Sem perder tal perspectiva multidisciplinar, este trabalho explorou, com base nas representações sociais, significados presentes na adesão de mulheres, em tratamento de dependência química, a um programa de práticas corporais ${ }^{4}$, na forma de jogos e ginástica. Desta forma, o presente texto traz reflexões sobre como as participantes percebem-se em relação a esse programa no seu processo de recuperação.

Particularmente, analisa-se o modo como seu imaginário ordena essas percepções quando o discurso científico e terapêutico sobre as práticas corporais as justifica, predominantemente, por um viés biológico e funcionalista. No processo de recuperação, é procedimento difundido o consumo de líquidos associado à realização de esforço corporal. Há muito tempo sabe-se que o suor é um veículo para excreção de drogas e seus catabólitos (Kidwell, Blanco, Smith, 1997). Assim, o efeito desejado é o aumento da transpiração e conseqüente excreção desses produtos por meio do suor.

\section{Aspectos metodológicos}

A pesquisa caracterizou-se como pesquisa-participante, uma vez que os pesquisadores não procederam somente à descrição direta das características do fenômeno, mas também interagiram na realidade investigada, na qualidade de atores.

Para tanto, foi necessário o planejamento de atividades em consonância com o grupo pesquisado. Em termos gerais, a intervenção constituiu-se pela realização de práticas corporais como: ginástica localizada, ginástica aeróbica, alongamento, jogos de aventura e atividades de recreação, por um período de sete meses, numa instituição de recuperação para mulheres, sendo realizadas 55 aulas. A intervenção foi desenvolvida duas vezes por semana, com duração de uma hora por encontro.

A população deste estudo foi constituída por mulheres com dependência química em recuperação numa instituição filantrópica de Maringá-PR. Oriundas de famílias com renda abaixo de quatro salários-mínimos, todas eram alfabetizadas, tendo as mais jovens interrompido os estudos (Ensino Médio e, no caso de uma, Ensino Superior) em decorrência do consumo de drogas. Quanto às drogas ingeridas pelas mulheres, foram identificadas, em ordem decrescente: álcool, cocaína, maconha, com casos de associação das três ${ }^{5}$. Outras drogas também citadas, em menor recorrência, foram: tabaco, heroína, ecstasy, quinino e cafeína. Ao todo, participaram 14 mulheres, com idade entre 19 e 51 anos $^{6}$, todas em fase de recuperação e internas. Elas consentiram em participar do estudo, sendo garantido o anonimato das informantes (aqui numeradas de 1 a 14). A pesquisa foi aprovada pelo Comitê de Ética da Universidade Estadual de Maringá - UEM (parecer n.219/2004).

Além das observações diretas, foram realizadas entrevistas estruturadas em dois momentos do trabalho. O primeiro momento diagnóstico foi realizado com

\author{
${ }^{4}$ Prática corporal é \\ entendida como toda \\ manifestação gestual, \\ como os exercícios, os \\ jogos e as danças, com \\ significado cultural \\ compartilhado em \\ determinado contexto. \\ O termo atividade física \\ é utilizado para designar \\ quando as práticas \\ corporais são pensadas \\ em relação ao esforço \\ ou gasto energético \\ demandados. Aqui o \\ termo recreação refere- \\ se à condução de \\ atividades lúdicas \\ destinadas, \\ predominantemente, à \\ diversão.
}


o objetivo de identificar o grupo amostral, as causas que o levaram à utilização de drogas e os tipos de drogas consumidas. Também foram obtidas informações sobre as atividades físicas, esportivas, artísticas e recreativas anteriormente praticadas no tempo livre, e de que forma a Educação Física poderia contribuir para a saúde do grupo. No segundo momento foram feitas discussões sobre as representações das mulheres investigadas acerca de seus corpos e da ação das práticas corporais realizadas sobre eles.

Ao tomar as representações sociais como conhecimento-comum a determinado grupo, assume-se sua constituição com base na interpenetração entre objetividade e subjetividade. Nesse sentido, salienta Minayo (1998), ao se buscar, na área da saúde, compreender os significados, tanto de ações quanto de pensamentos, sentimentos e resistências de grupos populacionais, deve-se considerar tanto o discurso quanto a base técnica.

Para Menéndez (1998), a medicina praticamente se preocupa com as representações e hábitos da população quando eles incidem negativamente sobre a saúde. Todavia, cada "grupo social, independente de seu nível de educação formal, gera e utiliza critérios de prevenção frente aos padecimentos que, real ou imaginariamente, afetam sua saúde na vida cotidiana." $E$, ainda, todos os grupos são possuidores de um saber frente aos padecimentos, visto que eles "são estruturais a toda cultura, já que são decisivos para a produção e reprodução da mesma" (Menéndez, 1998, p.75).

$\mathrm{O}$ autor considera fundamental dar-se atenção às representações e ações coletivas na efetivação de programas de saúde, mas adverte que, seja no conhecimento comum ou no acadêmico, os conceitos não são neutros estando ligados, conscientemente ou não, a teorias produzidas dentro de um marco referencial específico. Conforme outros marcos teóricos usam o mesmo conceito, pode haver discrepância, antagonismo ou complementaridade. É preciso, portanto, ir à raiz dos entendimentos, evitando tomar como evidentes os significados do discurso.

Minayo (1999) reitera esse cuidado lembrando que as falas não podem ser tomadas como expressão pura da verdade, sob o risco de se acreditar serem os discursos transparentes, sem contaminação de interesses, falhas de memória e ação da ideologia. Tal perigo ocorre quando se percebe o real sem questioná-lo, tomando o familiar como verdadeiro. Na investigação social, a análise do material objetiva aumentar a compreensão de determinado aspecto cultural para além do nível espontâneo da mensagem tomada como evidente.

Logo, as representações de qualquer pessoa investigada podem corresponder ao oposto do que está sendo relatado. Por isso, a observação participante foi fundamental para conferir outras falas, gestos e ações gerados espontaneamente (ou não) durante o cotidiano da instituição.

\section{Resultados e discussão}

Ao discutirem a contribuição específica do programa de práticas corporais orientado por profissional de Educação Física, embora diversas facetas fossem lembradas, as mulheres destacaram a visão do esforço como uma forma de aquecer o organismo, levando-o a expelir substâncias químicas pelo processo de sudorese. Uma parcela significativa da população avaliada $(62,5 \%)$ consegue lembrar-se, exclusivamente, da ação catabólica, conforme explicitado nestas falas:

Sim, pois dizem que é bom transpirar para a desintoxicação. (Entrevistada 01)

Ajudando a expelir do organismo a química do corpo e ocupando a mente. (Entrevistada 05)

Ajuda na eliminação das toxinas. (Entrevistada 06)

Pode contribuir eliminando as toxinas do corpo. (Entrevistada 08)

Entretanto, em relação à bioquímica e à fisiologia, poderá a representação sobre o efeito catabólico do exercício corresponder à realidade? O fato de o uso de álcool e drogas ilícitas poder ser 
diagnosticado em amostras de sangue, urina, cabelo, saliva, tecido adiposo, pele, suor e outros tecidos (Behrensdorf \& Steentoft, 2003), deve-se à presença da própria droga nesses locais ou de compostos resultantes de seu catabolismo. Embora seja conhecido, há muito tempo, que as drogas podem ser excretadas pelo suor, não existem relatos de trabalhos que tenham quantificado a ação da atividade física na recuperação de dependentes químicos em função da maior eliminação da droga pela sudorese.

Os vários mecanismos pelos quais as drogas podem ser secretadas no suor incluem a difusão passiva da droga do sangue para as glândulas sudoríparas e a migração transdérmica da droga através da pele (Follador et al., 2004; Huestis et al., 1999).

A concentração das drogas no suor varia com uma série de fatores, dentre eles a concentração da droga no sangue e a intensidade da transpiração (Huestis et al., 1999). Considerando a difusão passiva da droga da corrente sanguínea para o suor, a prática da atividade física, como parte do processo terapêutico, levaria ao aumento do fluxo sanguíneo e da transpiração, aumentando esta via de excreção da droga e seus catabólitos.

Quando questionadas sobre a origem desse saber, as internas revelaram que se trata de um conceito adquirido do discurso biomédico, difundido em revistas ou nas casas de tratamento. $\mathrm{Na}$ verdade, parece ser uma informação presente em vários ambientes, como revela a Entrevistada 12: "Aprendi na faculdade; em clínica de recuperação. Li em livros que a atividade física deve ser priorizada como auxiliar no tratamento de dependência química".

Surpreende, porém, observar que o lócus desse aprendizado teórico tem sido mais os ambientes escolares, destacando-se as aulas de Educação Física sobre saúde. O senso comum criado sobre o esporte não ser droga e, portanto, contribuir para a aquisição de saúde e manter a juventude longe dos vícios, vem colocando as aulas de Educação Física à frente das campanhas escolares de prevenção ao uso de substâncias psicoativas. Pelas informações veiculadas, os conteúdos da cultura corporal acabam sendo reduzidos a funções sociais ou fisiológicas.

Uma dificuldade na hegemonia assumida por essa disciplina escolar na prevenção ao consumo de drogas é que esta venha a tomar tal problemática exclusivamente com base em seu ponto de vista (e, o que é pior, em só uma de suas abordagens), com tendência a buscar uma causalidade única.

Como adverte Menéndez (1998, p. 75), "isolar o risco de beber, de fumar ou de comer determinados alimentos pode ser eficaz para intervir no nível de condutas individuais, mas não só anula o efeito compreensivo do problema, senão que reduz a eficácia da intervenção". O autor se remete ao exemplo do fumo no Reino Unido, mais difícil de ser abandonado entre pobres que nos extratos superiores. Então, pergunta o autor, não seria a classe econômica/social o condicionante? Entre a classe trabalhadora britânica, hábitos como fumar, ingerir cerveja, ter contatos corporais violentos e conviver socialmente no pub, expressam o modo de existir socialmente, a identificação cultural e a idiossincrasia dessas pessoas, o que motivaria a sobrevivência dessas atitudes consideradas nocivas à saúde (Menéndez, 1998).

Corroborando essa inquietação, as participantes da pesquisa, quando questionadas sobre suas atividades de lazer antes da dependência química, informaram, basicamente, atividades físicoesportivas (sobretudo caminhada e esportes de quadra) e leitura. Sua participação em práticas corporais e acesso à informação, embora se possa questionar a qualidade de ambas, parece não têlas blindado ou protegido do consumo e dependência de drogas, particularmente álcool e cocaína, as mais consumidas entre elas.

As conversas com as mulheres dependentes químicas sugerem, entre outros aspectos, que elas atribuem ao componente individual a razão principal para o abuso e dependência de substâncias, relacionando-os à personalidade da pessoa. Já que se exercitavam e estavam informadas sobre a temática, essas mulheres só poderiam concluir pela sua "culpabilização", imputando-se como responsáveis. Por esse exemplo, nota-se como, apesar da multicausalidade das enfermidades, os atingidos pelas doenças tendem a assimilar a responsabilização a uma causa específica.

Embora não fossem levadas a refletir sobre a parcela da influência hereditária, socioeconômica e ambiental na dependência, as internas apontaram variadas dimensões (genética, religião, sociedade, comunidade, família, indivíduo) da totalidade quando se remetiam às condições intervenientes à sua 
recuperação. Nesse caso, a instituição de tratamento Ihes encoraja a planejarem a vida durante e após a internação, sob diferentes aspectos (vida familiar e comunitária, trabalho, lazer, espiritualidade).

Sobre esse parcelamento do indivíduo e de sua saúde em diversos componentes, sempre em conflito, nunca em equilíbrio, nota-se, como Helman (2003, p. 27), uma automação na imagem do corpo social. Para a autora, tal como a sociedade ocidental se enxerga como indivíduos autônomos, o corpo é tomado como uma junção de partes individuais que podem ser trabalhadas sem ameaçar a sobrevivência do todo.

Devido a esse parcelamento do corpo e de suas funções, o estudo acabou por encontrar um olhar diferenciado da Educação Física no grupo de dependentes químicas. Como já referido, a contribuição do movimentar-se é, sobretudo, relacionada à sudorese. A prática corporal fica sendo representada como algo que extrai humores do interior do corpo (dentro da pele) para expelilos pelos poros da epiderme (a barreira que separa o 'eu corpo' do mundo exterior). Não se trata da cultura corporal como algo que amplia as sensações possíveis a partir do invólucro epidérmico, mas de restringir a representação sobre o mesmo a relações instrumentais.

Em complemento, a visão higienista dessa relação faz do corpo um receptáculo que, por enfraquecimento físico e moral, ingere substâncias maléficas à saúde do indivíduo. Cada qual deve aquecer seu corpo, preferencialmente por meio de movimentos aeróbios vigorosos que, além de serem úteis à transpiração, são simbolicamente eficazes para se incorporar valores ascéticos ${ }^{\top}$.

Se o fundamental fosse transpirar, a sauna seria uma solução mais objetiva, recorrente a existência de versões medicalizadas reproduzindo leituras morais. Helman (2003) exemplifica com as representações coletivas, na medicina, sobre as causas da obesidade. As pesquisas sobre esse tema indicam que o diagnóstico causal sobre "comer muito e exercitar-se pouco" seriam traduções recentes de alguns pecados capitais. Na raiz da questão reitera-se a desaprovação moral da gula e da preguiça, assim como da falta de autocontrole. todavia fica evidente que o movimentar-se cumpre, também, uma função social. Certas práticas corporais conduzem à assimilação de um autocontrole. E um corpo suado pela 'malhação', embora esteja longe de ser agradável, expressa aos olhares de todos - a determinação do dependente químico em desincorporar as drogas de seu organismo e, por assim representado, de seu íntimo.

Neste caso, esse é um conceito já assimilado na sociedade e reforçado institucionalmente. Conhecimento que as internas acabam reiterando sem, contudo, mediarem-no com suas próprias sensações e reflexões, visto que nem em suas conversas espontâneas expressam sua opinião particular sobre como sentem os benefícios dessa eliminação da droga e seus catabólitos. Pelo contrário, quando a maioria refere-se aos benefícios da prática corporal com base em suas sensações, a representação predominante diz respeito ao relaxamento (psíquico/somático) decorrente da atividade.

Em relação à percepção de seu corpo em função da introdução do programa de práticas corporais na casa de recuperação, as respostas correspondem ao pressuposto de que essa experiência, mais que se constituir numa forma direta e utilitarista de tratamento é, primeiramente, uma forma de a pessoa relacionar-se com o corpo. A efetiva capacidade de melhorar o amor próprio e a auto-estima é o que torna a prática corporal um componente benéfico e, a longo prazo, um fator contribuinte para a qualidade de vida da pessoa, incluindo o dependente químico.

Esses resultados parecem corroborar a discussão de Carvalho (2001) sobre a importância de considerar o "sujeito" da ação como o foco de nossa reflexão, ao invés de priorizar a relação atividade física e saúde. A intervenção em Educação Física, por esse pressuposto, se deslocaria da busca da saúde individual para focar no sujeito coletivo. E a saúde? Conforme a autora, ao 
proporcionar contato com os conteúdos da cultura corporal, o profissional da área fomentaria saberes que auxiliariam cada indivíduo a ser mais emancipado e consciente. Assim, este poderia tomar suas próprias decisões e edificar as estratégias mais coerentes com sua maneira de viver melhor em sua coletividade.

Para tanto, é necessário acessar esse sujeito coletivo da relação "atividade física e saúde", adentrando sua forma de pensar. Não obstante, vale advertir que as representações sociais são construções plurais, sujeitas a contradições e à conciliação de pensamentos opostos. Assim sendo, tanto se vê um indício desse viés de prática corporal manifestar-se como busca pelo prazer quanto como uma espécie de remédio eficaz à promoção de algumas dimensões da saúde. Estas respostas dizem respeito à percepção corporal que as internas tiveram com sua adesão ao programa:

No começo dói, mas depois relaxa o corpo e fica super bem. (Entrevistada 09)

Sim, quando faço atividade física durmo melhor, como melhor, penso melhor e meu corpo agradece. (Entrevistada 12)

Sim, eu me sinto mais leve. (Entrevistada 14)

A esse respeito, poderia ser resgatada a capacidade de os jogos e exercícios estimularem momentos de catarse. Em acréscimo, a prática corporal de lazer está associada à liberação de substâncias (endorfinas) que agem sobre o cérebro, proporcionando prazer e relaxamento. De acordo com Sher (2001), os opióides endógenos estão envolvidos na mediação do humor e os exercícios, por aumentarem a liberação destes compostos, contribuem para o equilíbrio do humor nos seres humanos. Frente à representação do corpo como um depositório de substâncias tóxicas que devem ser expelidas, o prazer evocado pelo relaxamento mostra-se um canal menos mecânico para se trabalhar o imaginário das dependentes químicas acerca da importância das práticas corporais em sua recuperação e inserção social.

Gimeno et al. (1998) reforçam essa compreensão ao comentarem os efeitos da introdução de jogos cooperativos e práticas de aventura numa instituição espanhola para tratamento de dependentes químicos. Os jogos cooperativos objetivaram restabelecer a sociabilidade em parâmetros de confiança. Já a aventura, além de reforçar a necessidade do outro para sobreviver nas situações de risco, possibilitou que ocorresse uma descarga adrenérgica frente à percepção de um perigo e, posterior à superação do mesmo, a liberação de opiáceos.

Embora não seja conclusiva, a relação entre jogos de vertigem e drogas é sugestiva e revela ambigüidades, pois parece tanto contribuir para o ingresso quanto para a 'suspensão' do consumo de entorpecentes. Para Caillois (1994), as drogas seriam a corrupção (exagero) da vertigem (ilinx), que é um impulso primário da condição humana.

De fato, tanto o uso de drogas quanto a prática de esportes radicais produzem sensações de vertigem (representada como emoção, adrenalina). A adrenalina "vicia", fazendo com que o sujeito busque, cada vez mais, a repetição da atividade que leva à sua liberação. Ademais, há as endorfinas, que são analgésicos naturais que entram em cena logo após a adrenalina, como uma resposta a esse hormônio, causando uma sensação muito agradável de entorpecimento e bem-estar e cessando as dores. Para Gimeno et al. (1998), os jovens em tratamento estudados por eles buscavam trocar a dependência química por uma vertigem natural e socialmente aceita (circo, caiaque, rapel).

A análise de Caillois (1994) enriquece essa compreensão ao demonstrar que o alcoolismo e o consumo de drogas são, em tese, um transbordamento do lúdico reprimido no cotidiano. O autor considera que a vida civilizada em sociedade, como existe hoje, exigiu a marginalização da vertigem, que acabou resistindo em formas degradadas e diluídas. A intensificação das ações em função da produtividade capitalista, exigindo um corpo que atendesse ao ritmo das novas tecnologias, e o gosto pela velocidade, que tomou conta do homem moderno são, conforme Caillois (1994), sobrevivências da vertigem no cotidiano.

Tal contaminação estendeu-se para o campo perceptivo e sensorial de modo que o fenômeno das 
drogas foi apenas uma das formas de as pessoas tentarem se adaptar a um ritmo de produção cada vez mais vertiginoso. Quando a atitude psicológica diante da vertigem se extravia de seu equilíbrio, pode-se diagnosticar que boa parte da tensão vital, entre jogo e vida cotidiana, prosperou na busca de uma vida alucinógena, excitante e imagética, que exclui a realidade, pelas drogas e álcool.

Logo, o frenesi na forma como a sociedade produz e se reproduz é obstáculo fundamental para se conseguir viver sem consumir drogas. Não é por acaso que as instituições de tratamento precisam localizar-se em áreas naturais ou rurais, impondo um outro ritmo e uma concepção menos linear de tempo, para que consigam obter avanços na recuperação do dependente químico. Embora, quimicamente, o organismo dessas pessoas vá sempre sentir os efeitos da abstinência das drogas, uma iniciativa no período pós-alta, que parece contribuir com o tratamento e enfrentamento do cotidiano, seria poder optar por uma relação menos compulsiva com o tempo social e a devolução da vertigem ao seu verdadeiro lócus, o lúdico (daí os jogos de aventura).

Feita essa reflexão, vale retomar o contexto do estudo, questionando sobre como a intervenção da Educação Física pode vir a somar-se com outras iniciativas para uma política de fortalecimento do dependente químico na sociedade. É importante lembrar que as práticas corporais foram admitidas na instituição por se acreditar na sua complementaridade à oração e ao trabalho terapêutico, pois a direção da instituição acredita na recuperação do indivíduo em três níveis: físico, mental e espiritual. Logo, foram pensadas numa perspectiva de atividade física e recreação. Não obstante o limite dessa visão (idealista) de saúde, tal contribuição não se restringiria somente ao tratamento, mas perduraria por toda a vida, quando as mulheres, ao saírem da recuperação, continuariam envolvidas com práticas corporais significativas em seu tempo livre.

Sem desejar reforçar uma postura compensatória ou utilitarista, percebe-se que, considerando a realidade estudada, as práticas corporais de lazer proporcionaram sensações de prazer às mulheres que delas participaram. Essas 'novas' fontes de satisfação podem contribuir para que se opere a substituição da recompensa percebida ao se consumirem substâncias químicas. O corpo deixa de ser espaço de perdas (de substâncias) para se transformar em um território de produção de sensações agradáveis. Sua vivência não é atrelada a uma função social, mas começaria a apresentar-se mais autodeterminada pelo sujeito da ação.

Por isso mesmo, indagamos sobre as perspectivas das internas. As respostas mais freqüentes foram: reconstituir família, estudar, ajudar outros dependentes químicos, buscar sucesso profissional e ter prática corporal regular. Em relação às atividades corporais pretendidas, foram lembradas, em ordem decrescente: ginástica (localizada e hidroginástica), caminhada, lutas, natação, e esportes coletivos. As atividades de aventura foram citadas apenas entre as internas mais jovens.

Interessante notar que a representação sobre a sudorese perde força em relação ao futuro. As internas planejam a prática corporal para a fase de inserção na sociedade pensando em objetivos estéticos (emagrecimento) e de saúde integral:

Fazer ginástica localizada porque além de manter o corpo beneficia a mente. (Entrevistada 14)

Um exercício que ajuda fisicamente e mentalmente. (Entrevistada 08)

Encontrar o equilíbrio entre corpo, alma e espírito. [...] Consegui emagrecer dez quilos com abdominais e voleibol. (Entrevistada 02)

Mesmo que soe previsível a predileção feminina pela ginástica localizada, independente de sua condição como dependente química e, como segunda opção, a caminhada, é preciso questionar qual a possibilidade dessas mulheres efetivarem suas intenções após o período de tratamento. Embora a caminhada seja uma atividade possível de ser realizada em praças, ruas e parques públicos, as representações apontam para uma visão predominantemente de consumo quando se pergunta, às mulheres, o local no qual podem praticar a atividade desejada. Estas se imaginam em clubes ou academias. Mesmo sendo estimado um custo para matrícula e mensalidades, é forte a representação da academia como local ideal. 
Dois aspectos complementares, mas antagônicos, precisam ser desmembrados da constatação sobre a hegemonia da academia entre as representações sociais. Primeiramente, os custos podem representar baixa adesão e aderência a alguma atividade física regular, levando tanto a sentimentos de frustração como reiteração do conformismo cultural e baixa criatividade. Vale acrescentar que o entendimento do problema como de resolução individual pode reforçar a limitada mobilização social em torno de reivindicações por políticas públicas de esporte e lazer voltados à saúde. Aliás, a busca por academia e outros empreendimentos particulares referenda a gradual substituição do poder público pela rede privada, a qual, geralmente, não está acessível aos grupos especiais e mais carentes da sociedade (Carvalho, 2001).

Mas, por outro ponto de vista, o desejo de fazer ginástica em academia pode ser interpretado para além da querela em torno da privatização dos equipamentos de lazer físico-desportivo. Metade das entrevistadas, ao manifestarem o desejo por freqüentar academias, estranhamente não possuíam vivência desse ambiente. Seu imaginário, aliás, parece mais conduzido pelas expectativas em relação a redes de sociabilidade e ao prazer estético em meio à exibição de corpos saudáveis. $\mathrm{E}_{\text {, }}$ considerando a apreensão e insegurança da pessoa após tratamento, estar na academia, ao invés de em lugares públicos e abertos, pode significar a busca por um local seguro e, ao mesmo tempo, com mais vigilância e cobrança por atitudes consideradas saudáveis. Para elas, a presença dos colegas e do instrutor é um estímulo à aderência ao exercício, mesmo a custo de sua autonomia.

Um aspecto importante para essa reflexão é que a relação das mulheres com as práticas corporais e com as substâncias psicoativas é duplamente desfavorável: as mulheres têm menos acesso às oportunidades físico-esportivas de lazer (Pitanga \& Lessa, 2005) e possuem menos chance de ter uma boa evolução na recuperação quando comparadas aos homens (Kerr-Corrêa et al., 1999).

Por fim, quando essas mulheres se referem à busca do equilíbrio, vale recorrer ao questionamento teórico dessa visão idealizada de saúde, pois nem sempre as condições necessárias para esse equilíbrio estão disponíveis. Como salienta Carvalho (2001, p. 14) "tem saúde quem tem condições de optar na vida". Estariam imbricados não somente o suposto equilíbrio físico-mental-espiritual (até porque é necessário desequilibrar-se para se equilibrar), mas possibilidades relativas às condições de vida tanto em sua totalidade, quanto no acesso ao lazer, trabalho, cuidados à saúde e educação. Porém, essas políticas parecem não produzir efeito na sociedade brasileira, cuja velocidade compulsiva tem servido a um modelo de desenvolvimento desigual. Assim, já em sua gênese, a política de inclusão do dependente químico resultaria em sua exclusão.

\section{Considerações}

Algumas limitações podem ser citadas para o presente estudo. Como limitante podemos destacar o fato de que as entrevistas foram realizadas no espaço físico da instituição e, mesmo garantindo o anonimato absoluto, isso pode ter interferido nas falas das participantes, que podem ter se sentido vulneráveis e, por isso, omitido ou camuflado sentimentos e emoções. Embora todas as mulheres internas na instituição tenham participado do estudo, outro fato a destacar seria o tamanho da amostra que, por ter sido pequeno, costuma ser considerado um fator limitante, não permitindo generalizações. Todavia, ao buscar um contexto particular, este trabalho ensejou justamente desestabilizar os discursos fundados nas generalizações.

Afinal, é válido que cada grupo possua sua própria visão de mundo e de saúde. Helman aponta (2003, p. 94) que, em "sociedades culturalmente mistas, um modelo único e inflexível de saúde não pode ser mais aceitável. Por isso a medicina tem de ser ciência social aplicada além de ser ciência médica aplicada". Assim, uma visão crítica do ser humano em sociedade não implica a negação de outros campos do saber (Carvalho, 2001), pois tão perigoso quanto o reducionismo biológico é o reducionismo social, sendo importante a consideração - contextualizada - dos diferentes saberes sobre saúde e sociedade (Minayo, 1998). 
No caso deste estudo, evidenciaram-se múltiplas representações coletivas passíveis de significar a cultura corporal sistematizada num grupo de mulheres dependentes químicas. Primeiro, destacou-se a consideração dessas mulheres sobre o exercício como meio de aumentar a sudorese, isto é, o transporte de substâncias indesejáveis para fora do organismo. Nessa representação, há coerência com discursos presentes na Medicina e na Educação Física. Vêem-se indissociáveis: os valores morais, cujo ascetismo apregoa o esforço físico como um sacrifício para se adquirir mais autocontrole; a visão biomédica de 'equilíbrio e desequilíbrio', para a qual o funcionamento saudável do corpo depende do equilíbrio harmônico de certos componentes dentro do corpo. A dependência seria decorrência da carência ou excesso de certas substâncias no corpo, havendo necessidade de se expelirem os catabólitos da droga.

Nessa transferência do 'mal' localizado nos humores para o suor, a pele delimita a territoriedade do corpo, divisa o 'eu interno' do mundo exterior, realizando trocas com esse meio, de forma a absorver sensações e experiências mas, também, eliminar substâncias indesejadas à homeostase corporal.

Porém, não se trata somente de fazer o corpo expelir. Há a dimensão de individuação que a pele proporciona, permitindo ao sujeito tomar contato sensível com a realidade e dando-lhe elementos para diferenciar o que é externo daquilo que é intrínseco ao corpo. Então, a prática corporal (seja recreativa, de aventura ou expressiva) com o dependente químico trata de fazer a pele receber, acariciar, respirar e relacionar-se. Estas possibilidades são vistas como múltiplas formas dessa peleterritório comunicar-se com a exterioridade, agindo sobre ela, e informar à interioridade sobre sensações como: tensão, dor, prazer, pressão, frio, calor ou vertigem.

Outras representações sobre o corpo estiveram presentes e precisariam ser consideradas, entre as quais a dimensão estética, revelando a subjetividade pautada pelo desejo de configurar um corpo belo, o qual pode redundar em um apelo mercadológico. Os gestos e falas das internas ainda evidenciaram resquícios de busca do prazer, relacionados a sentimentos de recompensa, relaxamento e excitação por meio das atividades. Estas, às vezes, desencadearam em momentos subversivos, tornando lícitos comportamentos proibidos na casa de recuperação (como, por exemplo, ouvir música não-religiosa).

Finalmente, em menor grau, as práticas corporais, como modo de (educação para o) lazer, foram referidas, pelas internas, como positivas ao processo geral de recuperação, influenciando no controle de condições particulares (como controle do estresse e da ansiedade, sociabilidade, qualidade e quantidade de sono). Para o dependente químico, essas carências são iguais ou mais importantes, pois a abstinência da droga desencadeia diversos sintomas, tornando necessária a ocupação do tempo com atividades.

Porém, o mero uso profilático das atividades, sem direcioná-las para o desenvolvimento das internas, desqualifica o papel pedagógico do profissional de Educação Física. Nesse sentido, há de se pensar nesses conteúdos físico-esportivos como uma dupla educação para a vida. Primeiro porque, por meio dessas atividades, conceitos (como o conhecimento sobre os efeitos do exercício na eliminação de toxinas) podem ser descobertos e rediscutidos pela práxis. Segundo, na perspectiva da autonomia, o próprio aprendizado dos exercícios e jogos pode vir a constituir-se como escopo para novas experiências, as quais podem ser incluídas no lazer dessas mulheres, após sua liberação.

Em complemento, é necessária uma política pública que organize esses aspectos ao longo do período de inserção do dependente químico na sociedade. Para tanto, urge identificar como cada coletividade cria estratégias para dar continuidade as suas experiências corporais na fase pósinternação, considerando a interação destas com o atendimento às outras condições de vida e seus limites numa sociedade já narcotizante em sua essência. A propósito, formar pessoas para autonomia, de modo que sejam capazes de escolher dentro das possibilidades existentes e, concomitantemente, lutar pela sua ampliação, é condição primeira quando se destaca a dimensão político-pedagógica da intervenção profissional. 


\section{Colaboradores}

Os autores Giuliano Gomes de Assis Pimentel, Edna Regina Netto de Oliveira e Aparecida Paulina Pastor participaram, igualmente, da elaboração do artigo, de sua discussão e redação. Giuliano Gomes de Assis Pimentel e Edna Regina Netto de Oliveira também participaram da revisão do texto.

\section{Referências}

BEHRENSDORFF, I.; STEENTOFT, A. Medical and illegal drugs among Danish car drivers. Accid. Anal. Prevent., v.35, p.851-60, 2003.

CAILLOIS, R. Los juegos y los hombres: la máscara y el vértigo. México: Fundo de Cultura Económica, 1994.

CARVALHO, Y.M. Atividade física e saúde: onde está e quem é o "sujeito" da relação? Rev. Bras. Ciênc. Esp., v.22, n.2, p.9-22, 2001.

FOLLADOR, M.J.D. et al. Detection of cocaine and cocaethylene in sweat by solid-phase microextraction and gas chromatography/mass spectrometry. J. Chromatogr. B, v.811, p.37-40, 2004.

GIMENO, J.M.R. et al. La prevención de drogodependencias mediante actividades cooperativas de riesgo y aventura. Apunts, n.59, p.46-54, 1998.

HELMAN, C.G. Cultura, saúde e doença. 4.ed. Porto Alegre: Artmed, 2003.

HUESTIS, M.A. et al. Sweat testing for cocaine, codeine and metabolites by gas chromatography-mass spectrometry. J. Chromatogr. B, v.733, p.247-64, 1999.

KERR-CORRÊA, F. et al. A importância da gravidade da dependência e do gênero para a evoluçäo de dependentes de drogas. Medicina (Ribeirão Preto), v.32, supl.1, p.36-45, 1999.

KIDWELL, D.A.; BLANCO, M.A.; SMITH, F.P. Cocaine detection in a university population by hair analisis and skin swab testing. Forensic Sci. Int., v.84, p.75-86, 1997.

MENÉNDEZ, E.L. Antropologia médica e epidemiologia. Processo de convergência ou processo de medicalização? In: ALVES, P. C.; RABELO, M. C. (Orgs.). Antropologia da saúde: traçando identidade e explorando fronteiras. Rio de Janeiro: Relemé Dumará, 1998. p.71-94.

MINAYO, M.C.S. O desafio do conhecimento. 6.ed. São Paulo: Hucitec, 1999.

Construção da identidade da antropologia na área da saúde: o caso brasileiro. In: ALVES, P.C.; RABELO, M.C. (Orgs.). Antropologia da saúde: traçando identidade e explorando fronteiras. Rio de Janeiro: Relemé Dumará, 1998. p.29-46.

OLIVEIRA, J.F; PAIVA, M.S.; VALENTE, C.L.M. Representações sociais de profissionais de saúde sobre o consumo de drogas: um olhar numa perspectiva de gênero. Ciênc. Saúde Coletiva, v.11, p.473-81, 2006. 
PITANGA, F. J.G.; LESSA, I. Prevalência e fatores associados ao sedentarismo no lazer em adultos. Cad. Saúde Pública, v.21, n.3, p.870-7, 2005.

SCIVOLETTO, S. et al. Relação entre consumo de drogas e comportamento sexual de estudantes de $2^{\circ}$ grau de São Paulo. Rev. Bras. Psiquiatr., v.21, n.2, p.87-94, 1999.

SHER, L. Role of endogenous opioids in the effects on light on mood and behavior. Med. Hypoth., v.57, n.5, p.609-11, 2001.

PIMENTEL, G.G.A.; NETO-OLIVEIRA, E.R.; PASTOR, A.P. Significados de las prácticas corporales en el tratamiento de la dependencia química. Interface - Comunic., Saúde, Educ., v.12, n.24, p.61-71, jan./mar. 2008.

El objeto de este estudio ha sido analizar las representaciones sociales de mujeres con dependencia química sobre la contribución de las prácticas corporales en su proceso de recuperación e inserción en la sociedad. Se entrevistaron a 14 internas de una institución de tratamiento, observándolas también en relación a la participación en un programa de prácticas corporales sistematizadas en forma de juegos y ejercicios. Las declaraciones y las prácticas demostraron contradicciones entre sensaciones, justificativas y perspectivas en relación al uso de sus cuerpos. Con base en los resultados se buscó comprender como las condiciones sociales de vida condicionan el modo por el cual esas mujeres se organizan en beneficio de su salud.

Palabras clave: Cuerpo. Salud. Dependencia química. Prácticas corporales. Educación Física.

Recebido em 15/03/06. Aprovado em 05/02/08 